\title{
Multilayer-Assembled Microchip for Enzyme Immobilization as Reactor Toward Low-Level Protein Identification
}

\author{
Yun Liu, \\ Hubert H. Girault, ${ }^{\perp}$ and Baohong Liu*,‡ \\ Department of Chemistry, Institutes of Biomedical Sciences, and Department of Macromolecular Science, Fudan University, \\ Shanghai 200433, People's Republic of China, and Laboratoire d'Electrochimie Physique et Analytique, \\ Ecole Polytechnique Federale de Lausanne, CH-1015 Lausanne, Switzerland
}

A microchip reactor has been developed on the basis of a layer-by-layer approach for fast and sensitive digestion of proteins. The resulting peptide analysis has been carried out by matrix-assisted laser desorption ionization timeof-flight mass spectrometry (MALDI-TOF MS). Natural polysaccharides, positively charged chitosan (CS), and negatively charged hyaluronic acid (HA) were multilayerassembled onto the surface of a poly(ethylene terephthalate) (PET) microfluidic chip to form a microstructured and biocompatible network for enzyme immobilization. The construction of CS/HA assembled multilayers on the PET substrate was characterized by AFM imaging, ATRIR, and contact angle measurements. The controlled adsorption of trypsin in the multilayer membrane was monitored using a quartz crystal microbalance and an enzymatic activity assay. The maximum proteolytic velocity of the adsorbed trypsin was $\sim 600 \mathrm{mM} / \mathrm{min} \mu \mathrm{g}$, thousands of times faster than that in solution. BSA, myoglobin, and cytochrome $c$ were used as model substrates for the tryptic digestion. The standard proteins were identified at a low femtomole per analysis at a concentration of 0.5 $\mathrm{ng} / \mu \mathrm{L}$ with the digestion time $<\mathbf{5 s}$. This simple technique may offer a potential solution for low-level protein analysis.

Progress in the field of biochemistry depends on new analysis techniques that allow studies to be performed on ever-decreasing sample volumes and target analyte concentrations. Many proteins are naturally expressed at low abundance. However, protein analysis at submicromolar concentration or trace levels is inherently difficult, mainly because of low digestion efficiency. Many techniques have been developed to enhance the digestion sensitivity for low levels of proteins. Mann ${ }^{1}$ developed digestion of low abundant samples in silver-stained gels. Ramsay ${ }^{2}$ reported rapid

\footnotetext{
* To whom correspondence should be addressed. E-mails: (Liu) bhliu@ fudan.edu.cn, (Yang) pyyang@fudan.edu.cn.

$\dagger$ These authors contributed equally to this research.

¥ Department of Chemistry, Institutes of Biomedical Sciences, Fudan University.

$\S$ Department of Macromolecular Science, Fudan University.

Ecole Polytechnique Federale de Lausanne.

(1) Shevchenko, A.; Wilm, M.; Virm, O.; Mann, M. Anal. Chem. 1996, 68, 850858.

(2) Lazar, L. M.; Ramsey, R. S.; Ramsey, J. M. Anal. Chem. 2001, 73, 17331739.

10.1021/ac051463w CCC: $\$ 33.50$ (C) 2006 American Chemical Society Published on Web 12/23/2005
}

digestion and analysis of small volumes of proteins using a microchip nanoelectrospray device and TOF spectrometry detection. $\mathrm{Li}^{3,4}$ proposed a method to digest proteins at low concentrations by a microcolumn filled with enzyme-adsorbing hydrophobic medium. Another alternative procedure is the immobilization of enzymes to digest small sample volumes in nanovials, or capillaries or on chips. Immobilized enzymes are considerably more stable and retain their catalytic activities for much longer time than free enzymes in solution.

The microfluidic chip is a potentially powerful tool which has been applied in such diverse research fields as sensors and chemical and biological reactors due to rapid and high-throughput analysis and minimized consumption of sample and reagent, as well as lower manufacturing cost. ${ }^{5-7}$ Several groups have explored the benefits of immobilized enzymes in microfluidic channels, which would have a significant impact on large-scale protein analysis. Sakai-Kato et al. ${ }^{8}$ developed a system consisting of a poly(methyl methacrylate) with a sample reservoir filled with trypsinencapsulated sol-gel. This on-chip microreactor was applicable to the digestion of protein with multiple cleavage sites and separation of digested products. Frechet ${ }^{9}$ reported that enzymatic microreactors were prepared on a microfluidic chip by immobilizing trypsin on porous polymer monoliths. Myoglobin could be digested in this way. In our group, poly(dimethylsiloxane) and poly(methyl methacrylate) substrates have been used to design microchip bioreactors using various approaches based on solgel entrapment, covalent binding, and physical adsorption. ${ }^{10-12}$

As one of the most attractive polymeric materials being used as substrate in microchip fabrication, poly (ethylene terephthalate) (PET) has already been employed for a practical bioanalysis

(3) Craft, D.; Doucette, A.; Li, L. J. Proteome Res. 2002, 1, 537-547.

(4) Craft, D.; Li, L. Anal. Chem. 2005, 77, 2649-2655.

(5) Olsen, K. G.; Ross, D. J.; Tarlov, M. J. Anal. Chem. 2002, 74, 1436-1441.

(6) Schilling, E. A.; Kamholz, E.; Yager, P. Anal. Chem. 2002, 74, 1798-1804

(7) Kopp, M. U.; de Mello, A. J.; Manz, A. Science 1998, 280, 1046-1046.

(8) Sakai-Kato, K.; Kato, M.; Toyo'oka, T. Anal. Chem. 2003, 75, 388-393.

(9) Peterson, D. S.; Rohr, T.; Svec, F.; Frechet, J. M. J. Anal. Chem. 2002, 74, 4081-4088.

(10) Wu, H. L.; Zhai, J. J.; Tian, Y. P.; Lu, H. J.; Wang, X. Y.; Jia, W. T.; Liu, B. H.; Yang, P. Y.; Xu, Y. M.; Wang, H. H. Lab Chip 2004, 4, 588-597.

(11) Qu, H. Y.; Wang, H. T.; Huang, Y.; Zhong, W.; Lu, H. J.; Kong, J. L.; Yang, P. Y.; Liu, B. H. Anal. Chem. 2004, 76, 6426-6433.

(12) Wu, H. L.; Tian, Y. P.; Liu, B. H.; Lu, H. J.; Wang, X. Y.; Zhai, J. J.; Jin, H.; Yang, P. Y.; Xu, Y. M.; Wang, H. H. J. Proteome Res. 2004, 3, 1201-1209. 
purpose interface to MS, electrochemical and fluorescence detection. ${ }^{13}$ However, the hydrophobic property of the PET leads to inefficiency in constructing a friendly interface with enzymes and biomolecules. To improve the immobilization of enzymes, many efforts have been devoted to surface modification, such as grafting polymerization, hydrolysis, plasma modification, coating of polymers, etc., to adjust such properties as wettability, adhesion and biocompatibility. Kang et al. ${ }^{14}$ carried out surface modification of PET films via UV-induced graft copolymerization with acrylic acid. Galactosylated surfaces were then obtained by coupling a galactose derivative. The galactosylated PET films were used as substrates for hepatocyte culture. Girault et al. ${ }^{15}$ presented a study of polymer surfaces by laser ablation for the purpose of controlling the electroosmotic flow in the PET microchannels.

The technique of layer-by-layer (LBL) assembly has been developed as a versatile method to functionalize surfaces. ${ }^{16-18}$ These LBL films have been employed in such diverse fields as biosensors, separation, integrated optics, surface modification, etc. The process is based on the sequential deposition of interactive polymers from their solutions by electrostatic, van der Waals, hydrogen bonding, and charge-transfer interactions. ${ }^{19}$ Because the LBL assembly facilitates the creation of functional material surfaces for the entrapping of proteins and enzymes, as well as drug molecules, it is attractive for applications in biocatalysis, immunosensing, and other biochemical analysis. The process is superior to other techniques for preparing multilayer thin films. The assembly is based on spontaneous adsorptions, no stoichiometric control is necessary to maintain surface functionality, and the assembled films have good thermal and mechanical stability. The physicochemical properties of films could be controlled by adjusting the deposition conditions or the outermost layer of the films. ${ }^{20}$

Compared with the commonly used synthetic polyelectrolytes, such as poly(styrenesulfonate) and poly(allylamine hydrochloride), the natural biomacromolecules chitosan (CS) and hyaluronic acid (HA), which are biocompatible, nontoxic, physiologically inert, and hydrophilic, offer the unique characteristic of a remarkable affinity to proteins and have been widely applied in medicine and biological research. Chitosan is a biopolymer derived from chitin. It is made primarily of repeating units of glucosamine, ${ }^{21}$ among which amino groups have been used in the immobilization of proteins. Furthermore, chitosan is positively charged in mildly acidic aqueous solutions, and its charge density is high. ${ }^{22}$ Thus, chitosan can be used as a polycation in a LBL assembly system, on which various polyanions can be adsorbed. Bearing negative charges, hyaluronic acid is also a highly hydrated polysaccharide of great biological interest, so they can be easily modified and

(13) (a) Rohner, T. C.; Josserand, J.; Jensen, H.; Girault, H. H. Anal. Chem. 2003 75, 2065-2074. (b) Lionello, A.; Josserand, J.; Jensen, H.; Girault, H. H. Lab Chip 2005, 5, 254-260.

(14) Ying, L.; Yin, C.; Zhuo, R. X.; Leong, K. W.; Mao, H. Q.; Kang, E. T.; Neoh, K. G. Biomacromolecules 2003, 4, 157-165.

(15) Bianchi, F.; Chevolot, Y.; Mathieu, H. J.; Girault, H. H. Anal. Chem. 2001, 73, 3845-3853.

(16) Decher, G.; Hong, J. D.; Schmitt, J. Thin Solid Films 1992, 210, 831-835.

(17) Lvov, Y.; Decher, G.; Mohwald, H. Langmuir 1993, 9, 481-486.

(18) Decher, G. Science 1997, 277, 1232-1237.

(19) Takeshi, S.; Miyuki, Y.; Mitsuru, A. Macromolecules 2002, 35, 8656-8658.

(20) Zhou, X. C.; Wu, L. Y.; Zhou, J. Z. Langmuir 2004, 20, 8877-8885.

(21) Vazquez-Duhalt, R.; Tinoco, R.; Antonio P. D.; Topolesk, L. D. T.; Payne, G. F. Bioconjugate Chem. 2001, 12, 301-306.

(22) Suh, J. K. F.; Matthew, H. W. T. Biomaterials 2000, 21, 2589-2598. coupled to various molecules. Up to now, both of them have mostly been used in hydrogel or membrane form for tissue engineering or drug delivery. ${ }^{23,24}$

In this paper, we propose a simple method of self-assembly for embedding enzymes on a poly(ethylene terephthalate) microfluidic chip as a microreactor for effective proteolysis. CS/HA multilayer films coating on the PET surface by electrostatic interaction could supply a biocompatible and hydrophilic microenvironment to accommodate a high amount of trypsin while preserving bioactivity. The on-chip enzymatic microreactor devised herein is well-suited for rapid and sensitive digestion of proteins. Coupled with MALDI-TOF MS, the modified microchip can identify standard protein samples in low concentrations down to $0.5 \mathrm{ng} / \mu \mathrm{L}$. This strategy could provide opportunities for sensitive detection and characterization of proteins at low levels.

\section{EXPERIMENTAL SECTION}

Materials and Chemicals. Poly(ethylene terephthalate) (PET) sheets (100- $\mu$ m-thick Melines) were purchased from Dupont (Geneva, Switzerland). Chitosan (medical grade, medium molecular weight) was obtained from Qingdao Heppe Biotechnology Co. Ltd. and was used as received. The microbial sodium hyaluronate NaHA (molecular weight $1.6 \times 10^{5}$ ) was a gift from CPN Ltd, Ústí nad Orlicí, Czech Republic. Bovine serum albumin (BSA, fraction V) was obtained from Bio Basic Inc. (Toronto, Canada), Cytochrome $c$, myoglobin, and trypsin were obtained from Sigma (USA). All of the other chemicals were of analytical grade and were purchased from the Shanghai Chemical Reagent Co. (Shanghai, China).

Fabrication of PET Microfluidic Chips. The microchip was fabricated by photoablation and thermal lamination as previously reported..$^{25}$ Briefly, the PET sheet was placed on computercontrolled $X-Y$ translation stages (Physik Instrumente, Germany) and scanned to be photoablated by a UV excimer laser (Argon Fluor Excimer Laser at 193 nm; Lambda Physik LPX 2051, Gottingen, Germany) for generating a 3-cm-length channel with a trapezoidal cross-section shape, about $42 \mu \mathrm{m}$ depth, $58 \mu \mathrm{m}$ width at the top, and $34 \mu \mathrm{m}$ at the bottom (see Supporting Information, Figure 1). The straight-line channel has photoablated reservoirs at each end. The PET with the microchannel, previously washed and modified, was finally thermally sealed by a PET layer at 110 ${ }^{\circ} \mathrm{C}$ using a lamination machine (Hangzhou Fengling electronic instrument Co. Ltd., Zhejiang, China).

PET Microchannel Surface Modification and Enzyme Immobilization. The structures of chitosan and hyaluronic acid are shown in Supporting Information Figure 2. The protocol of immobilizing enzymes on the LBL modified PET surface is depicted in Scheme 1. The PET chip was rinsed with distilled water and ethanol and then dried at room temperature. PET was hydrolyzed using $1 \mathrm{M}$ aqueous $\mathrm{NaOH}$ for $16 \mathrm{~min}$ at $60^{\circ} \mathrm{C}$ and subsequently protonated to prepare PET-COOH. ${ }^{26}$ This surface contained both carboxyl and hydroxyl functional groups and was negatively charged at sufficiently high $\mathrm{pH}$ 13. After hydrolysis,

(23) Thierry, B.; Kujawa, P.; Tkaczyk, C.; Winnik, F. M.; Bilodeau, L.; Tabrizian, M. J. Am. Chem. Soc. 2005, 127, 1626-1627.

(24) Thierry, B.; Winnik, F. M.; Merhi, Y.; Tabrizian, M. J. Am. Chem. Soc. 2003, 125, 7494-7495

(25) Roberts, M. A.; Rossier, J. S.; Rercier, P.; Girault, H. H. Anal. Chem. 1997, 69, 2035-2042.

(26) Chen, W.; McCarthy, T. J. Macromolecules 1997, 30, 78-86. 


\section{Scheme 1. Process Summary of the Encapsulation of Trypsin Based on Layer-by-Layer Self-Assembly with Oppositely Charged Polyelectrolytes on a Hydrolyzed PET Surface}
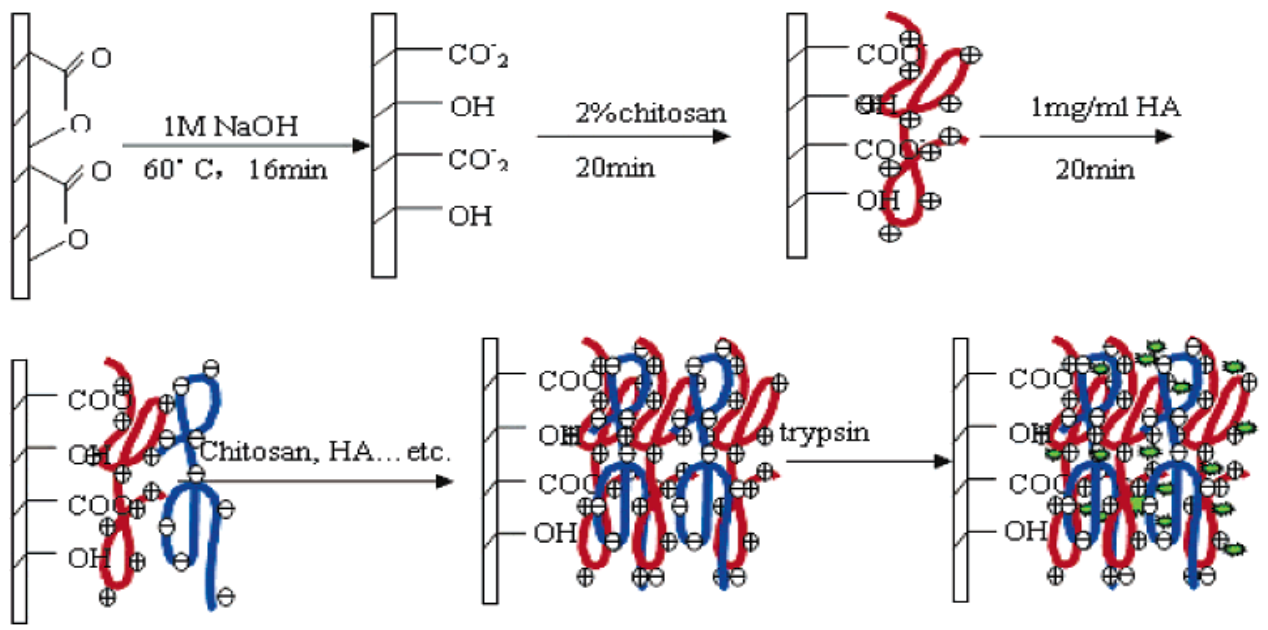

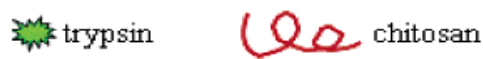

the PET film was washed with $0.1 \mathrm{M} \mathrm{HCl}$, distilled water, and ethanol and dried at reduced pressure. Subsequently, the PET film was incubated in chitosan solution $(1.0 \mathrm{w} / \mathrm{w} \%)$ for $20 \mathrm{~min}$ to adsorb a layer of positively charged chitosan, followed by rinsing with distilled water three times. In the next step, the charge polarity on the surface of the film was reversed by the adsorption of a layer of hyaluronic acid $(1.0 \mathrm{mg} / \mathrm{mL})$, followed by rinsing with water. With the alternate deposition, the amounts of trypsin immobilized were almost alike after a five-layer assembly, no matter what the outermost layer is, chitosan or hyaluronic acid. In this experiment, we chose nine assembled layers to ensure a maximum amount of immobilized trypsin. After the ninth layer of CS/HA assembly had been deposited, the film was dried at room temperature under reduced pressure. The LBL-modified PET chip was soaked in $5 \mathrm{mg} \mathrm{mL}^{-1}$ trypsin solution containing $50 \mathrm{mM}$ Tris $-\mathrm{HCl}$ buffer (pH 8.0) and $20 \mathrm{mM} \mathrm{CaCl}_{2}$ for at least 2 $\mathrm{h}$ at $4{ }^{\circ} \mathrm{C}$. Subsequently, the channel of the PET microchip was sufficiently washed by water to remove the unadsorbed trypsin.

Characterization of the Multilayer-Modified PET Surface. Attenuated Total Reflectance Fourier Transform Infrared (ATRFTIR) Measurement. The IR spectra were acquired using a Nicolet Nexus 470 instrument equipped with an attenuated total reflection (ATR) device. PET film was placed onto the ATR crystal (ZeSe).

Measurement of the Contact Angles. The static-state water contact angles were measured on the films of native PET and modified PET. A droplet of water was placed on the air-side surface of a film at room temperature. After $30 \mathrm{~s}$, the contact angle was determined using an OCA15 optical contact angle meter (Data Physics Company, Germany). An average of five measurements was utilized to evaluate each droplet.

Atomic Force Microscopy Imaging. The surface topography was assessed by an atomic force microscope (EC-SPM, Picoscan 2100) in tapping mode. Micrometer scanning was performed with nanosensor etched silicon probes. The instrument parameters were set as follows: scan size, $3.5 \mu \mathrm{m}$; resonance frequency, $60-$ $80 \mathrm{kHz}$. The images were flattened using the Nanoscope software.

Quartz Crystal Microbalance (QCM) Measurement. The controlled immobilization of trypsin in well-interconnected macroporous

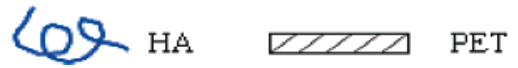

membranes was performed in situ with a quartz crystal microbalance (QCM) analyzer (CHI420, CH Instruments, Austin, TX) and quartz crystals $(7.995 \mathrm{MHz})$ sandwiched between two Au electrodes (area, $0.196 \mathrm{~cm}^{2}$ ). Chitosan, HA, and trypsin solution were assembled on the gold surfaces. The adsorption time for each deposition step was $30 \mathrm{~min}$, which was previously determined to be sufficient for saturation adsorption of polyions at the concentrations used. ${ }^{27,28}$ After deposition, the gold electrode surface was thoroughly rinsed with pure water and dried under nitrogen gas. The QCM frequency change in air was measured.

Activity Assay of the Immobilized Trypsin. The activity of the encapsulated enzyme in the microchip was examined by pumping BAEE ( $\alpha$ - $N$-benzooyl-L-arginine ethyl ester) solution (5$20 \mathrm{mM}$ ) in a $50 \mathrm{mM}$ Tris-HCL buffer (pH 8.0) using a 74900 series syringe pump (Cole-Parmer Instrument Co.) through the trypsin-adsorbing PET channel at a flow rate of $100 \mu \mathrm{L} / \mathrm{h}$. The resulting products were analyzed by a Capillary Electrophoresis System (P/ACE System 5000, Beckman). The capillary electrophoresis was run in phosphate buffer solution $(\mathrm{pH} 2.5)$ at $15{ }^{\circ} \mathrm{C}$ with UV detection at $214 \mathrm{~nm}$. The trypsin activity was calculated via the flow rate and absorbance difference.

On-Chip Protein Digestion and Identification. Protein solutions of cytochrome $c$ (Cyt-c), myoglobin, and bovine serum albumin (BSA) in $10 \mathrm{mM} \mathrm{NH}_{4} \mathrm{HCO}_{3}$ buffer solution ( $\mathrm{pH}$ 8.13) were driven through the LBL-modified PET microchannel by a syringe pump at a flow rate of $120 \mu \mathrm{L} / \mathrm{h}$. Effluents accumulated in the reservoir were collected by a digital pipet $(2-20 \mu \mathrm{L}$, Eppendorf Research) and then identified by MALDI-TOF MS. All MS experiments were performed on a 4700 Proteomics Analyzer with TOF/TOF Optics (Applied Biosystems, Framingham, MA). Each volume of $0.5-\mu \mathrm{L}$ sample solutions was dropped on the MALDI plate. After the solvent evaporated, a volume of $0.5 \mu \mathrm{L}$ of matrix solution ( $4 \mathrm{mg} / \mathrm{mL}$ CHCA dissolved in $50 \%$ aqueous $\mathrm{ACN} / 0.1 \%$ TFA) was dropped on the dried samples. The MS instrument was

(27) Lvov, Y.; Ariga, K.; Ichinose, I.; Kunitake, T. J. Am. Chem. Soc. 1995, 117, $6117-6123$.

(28) Onda, M.; Lvov, Y.; Ariga, K.; Kunitake, T. J. Ferment. Bioeng. 1996, 82, 502-506.

Analytical Chemistry, Vol. 78, No. 3, February 1, 2006

803 
operated at an accelerating voltage of $20 \mathrm{kV}$. A $200-\mathrm{Hz}$ pulsed Nd: YAG laser at $355 \mathrm{~nm}$ was used. Before identifying the samples, the MS instrument was calibrated with an internal calibration mode by tryptic peptides of myoglobin. All spectra were taken from signal-averaging of 800 laser shots with the laser intensity kept at a proper constant. GPS Explorer software from Applied Biosystems with Mascot as a search engine and SwissProt (version of 050303) as a database were used to identify proteins. All proteins were identified using the peptide fingerprint mass spectra combined with tandem mass spectra. The peptide mass tolerance was set to $80 \mathrm{ppm}$, and the tandem mass tolerance was set to $0.5 \mathrm{Da}$.

\section{RESULTS AND DISCUSSION}

Characterization of the Surface Properties of CS/HA Multilayer-Assembled PET. The design and processing of biointerface play an important role in biological analysis in the field of microfabrication. The multilayer assembly prepared as schematically depicted in Scheme 1 has been characterized by different techniques. To elucidate a continuously three-dimensional microstructured polyelectrolyte scaffold constructed, atomic force microscopy was employed to characterize the topographical property of the LBL-modified PET surface. It was clearly displayed that the surface was uniform with an RMS roughness of $318 \AA$, and many pores of tens to hundreds of nanometers distributed on the surface due to the coating of CS/HA multilayers, as shown in Figure 1a. The observed pores were well-interconnected through small pores or channels, which was essential for the free diffusion of substrates and efficient permeation of trypsin molecules into the multilayer-based microstructured network of CS/ HA on PET microchannels. Trypsin consists of single polypeptide chains, and the hydrophilic groups of the side chains are located on the surface. The microenviroment constructed by $\mathrm{CS} / \mathrm{HA}$ was hydrophilic and biocompatible with plenty of functional groups (such as amino, hydroxyl, and carboxyl groups) so that trypsin could be easily immobilized by electrostatic interactions and hydrogen bonds.

The ATR-IR spectra were recorded from the pristine PET surface and CS/HA-coated PET surface (as the outermost layer is CS or HA, respectively) (see Supporting Information Figure 3). The native PET spectrum showed a strong antisymmetric carbonyl stretching band at $1713 \mathrm{~cm}^{-1}$ of the esters, which was partially hidden under the HA bands in the case of spectrum $b$. It could be clearly observed that new and broad absorption bands above $3000 \mathrm{~cm}^{-1}$ and $\sim 1590$ to $1650 \mathrm{~cm}^{-1}$ appeared in the spectra of $\mathrm{b}$ and $\mathrm{c}$, which could be attributed to the functional groups $-\mathrm{OH},-\mathrm{NH}$, and $-\mathrm{NH}_{2}$ stretching, the amide $\mathrm{I}(\mathrm{C}=\mathrm{O}$ in $\mathrm{O}=\mathrm{C}-$ $\mathrm{NH}$, at $\left.1650 \mathrm{~cm}^{-1}\right)$, and amide II $(-\mathrm{NH}$ in $\mathrm{O}=\mathrm{C}-\mathrm{NH}$, at 1595 $\mathrm{cm}^{-1}$ ) bands, respectively. However, in the spectrum of the native PET, there were no distinct absorption peaks in the same range of wavenumbers. All of these facts have confirmed that chitosan and HA had built up on the PET surface.

The surface wettability corroborates the occurrence of the CS/ HA assembly on the PET film. The measurement of the contact angle is a simple and effective tool to investigate the surface property. ${ }^{29,30}$ Thus, it is possible to monitor the deposition process

(29) Hsieh, M. C.; Farris, R. J.; McCarthy, T. J. Macromolecules 1997, 30, 84538458.
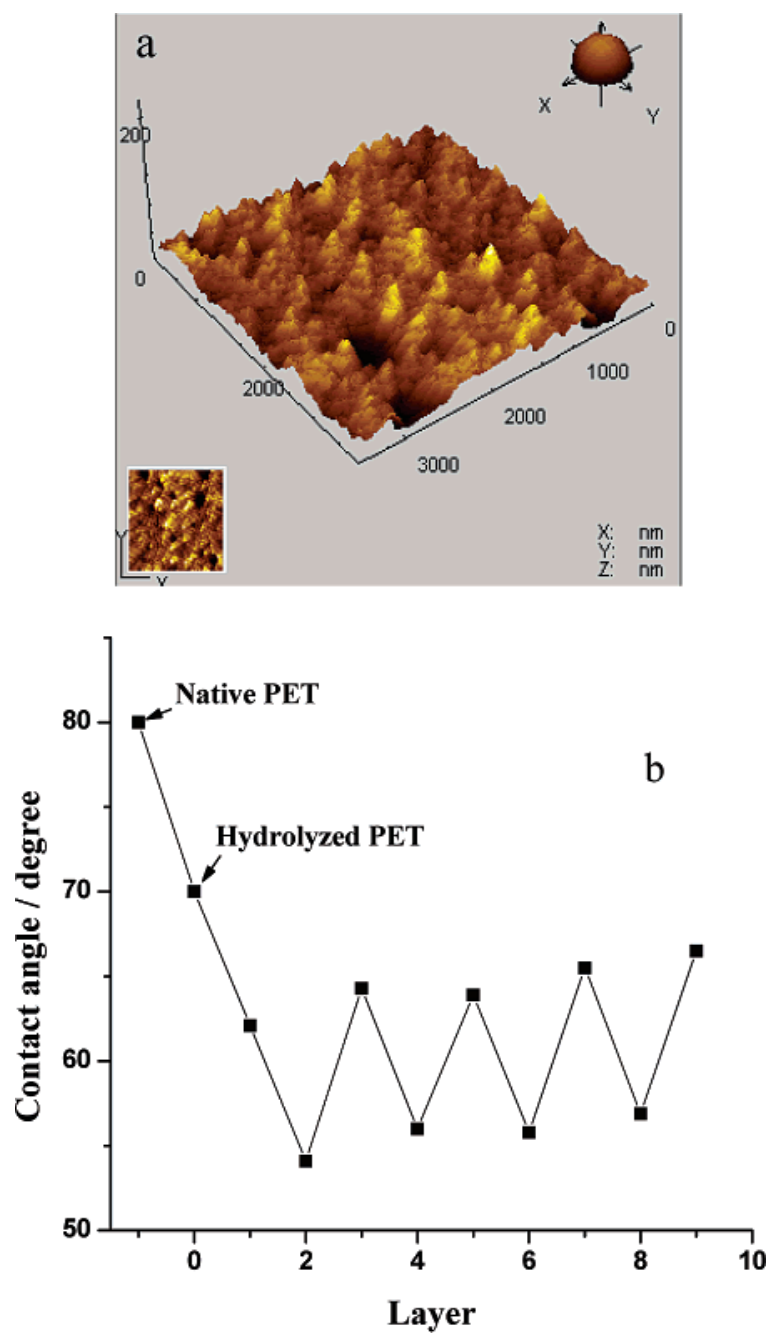

Figure 1. (a) AFM image (tapping mode) of the PET surface deposited by nine layers of chitosan/HA with the chitosan as the outermost layer. (b) Contact angle as a function of the layer number of chitosan and hyaluronic acid. Odd numbers represent films with chitosan as the outermost layer, whereas even number films have $\mathrm{HA}$ as the outermost layer.

by determining how the surface hydrophilicity changes. As shown in Figure 1b, the contact angle of the blank PET was determined to be $78.6 \pm 0.6^{\circ}$, indicating the hydrophobic surface of the native PET. After hydrolysis, the contact angle decreased to $70 \pm 1.4^{\circ}$, which was enough for the immobilization of hydrophilic macromolecules. Following the chitosan and hyaluronic acid adsorption, the contact angle of the film decreased and periodically fluctuated between $64.5^{\circ}$ and $55.7^{\circ}$. The obvious alteration of contact angle data verified the progressive buildup of the film by the deposition of polyelectrolytes. Additionally, the fluctuation of contact angles with the same outermost layer showed the interpenetration between neighboring CS and HA films where the segments of the underlying layer were able to influence the surface properties. ${ }^{30}$ The hydrophilic characteristics of CS and HA may improve the wetting of the microchannel walls, which are readily filled with aqueous substrate solutions to interact with immobilized enzymes.

Activity of the Adsorbed Trypsin in Microchannel. The assembly of trypsin in CS/HA membranes was monitored using

(30) Yoo, D.; Shiratori, S. S.; Rubner, M. F. Macromolecules 1998, 31, 43094318. 


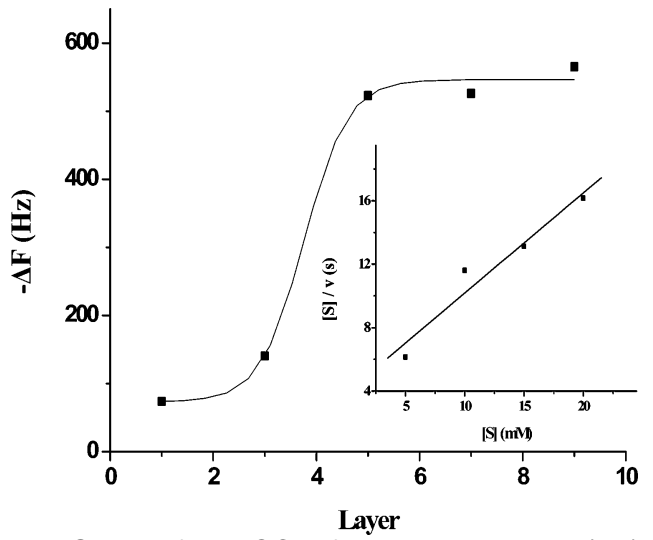

Figure 2. Graph of the QCM frequency changes $(\Delta F)$ for the different numbers of layers on which trypsin is immobilized. (Inset line) Hanes plots for trypsin encapsulated in microreactor based on nine CS/HA layers.

a quartz crystal microbalance. A continuous decrease in the $\mathrm{QCM}$ frequency shift, proportional to the mass deposited on the sensor surface, as a function of the number of layers confirmed the multilayer buildup. During the deposition, the thickness of the film and enzyme adsorption could be controlled by the different layers, CS/HA concentration, and deposition time. Figure 2 shows the QCM frequency changes $(\Delta F)$ for the different numbers of layers on which trypsin was adsorbed. A regular stepwise decrease in the QCM frequency was observed until reaching a plateau. The results showed that the amounts of enzyme were gradually reaching saturation after 5 layers. To guarantee the maximum amounts of enzyme adsorption, nine CS/HA layers were selected. According to the Sauerbrey equation, ${ }^{31}$

$$
\Delta F_{\text {air }}=-\left(1.83 \times 10^{4}\right) \Delta m_{\mathrm{A}}
$$

When trypsin was immobilized in the nine-multilayer matrix, $\Delta F$ was $-565.4 \mathrm{~Hz}$, which corresponded to a maximum enzyme coverage of $\sim 30 \mathrm{mg} / \mathrm{m}^{2}$. Generally, protein membranes prepared by the LBL assembly of polyelectrolytes (as well as other methods) typically yielded surface coverage values of $\sim 3-10 \mathrm{mg} / \mathrm{m}^{2}$ protein per layer. ${ }^{32,33}$

The activity of trypsin adsorbed in the CS/HA-assembled microchip was measured by monitoring the formation of BA, the digested product of BAEE. The BA was separated from BAEE by capillary electrophoresis and detected by adsorption at $214 \mathrm{~nm}$. The values of the Michaelis constant $\left(K_{\mathrm{m}}\right)$ and the maximum velocity $\left(V_{\max }\right)$ were determined by the Michaelis-Menton equation. ${ }^{34}$

$$
[\mathrm{S}] / v=\left(K_{\mathrm{m}}\right) / V_{\max }+\left(1 / V_{\max }\right)[\mathrm{S}]
$$

where $v$ is the velocity of the enzymatic activity and [S] is the concentration of substrate. The $K_{\mathrm{m}}$ values reflect the enzymatic affinities, whereas the $V_{\max }$ values reflect the activity of the encapsulated trypsin. $K_{\mathrm{m}}$ and $V_{\max }$ were calculated to be $6.1 \mathrm{mM}$ and
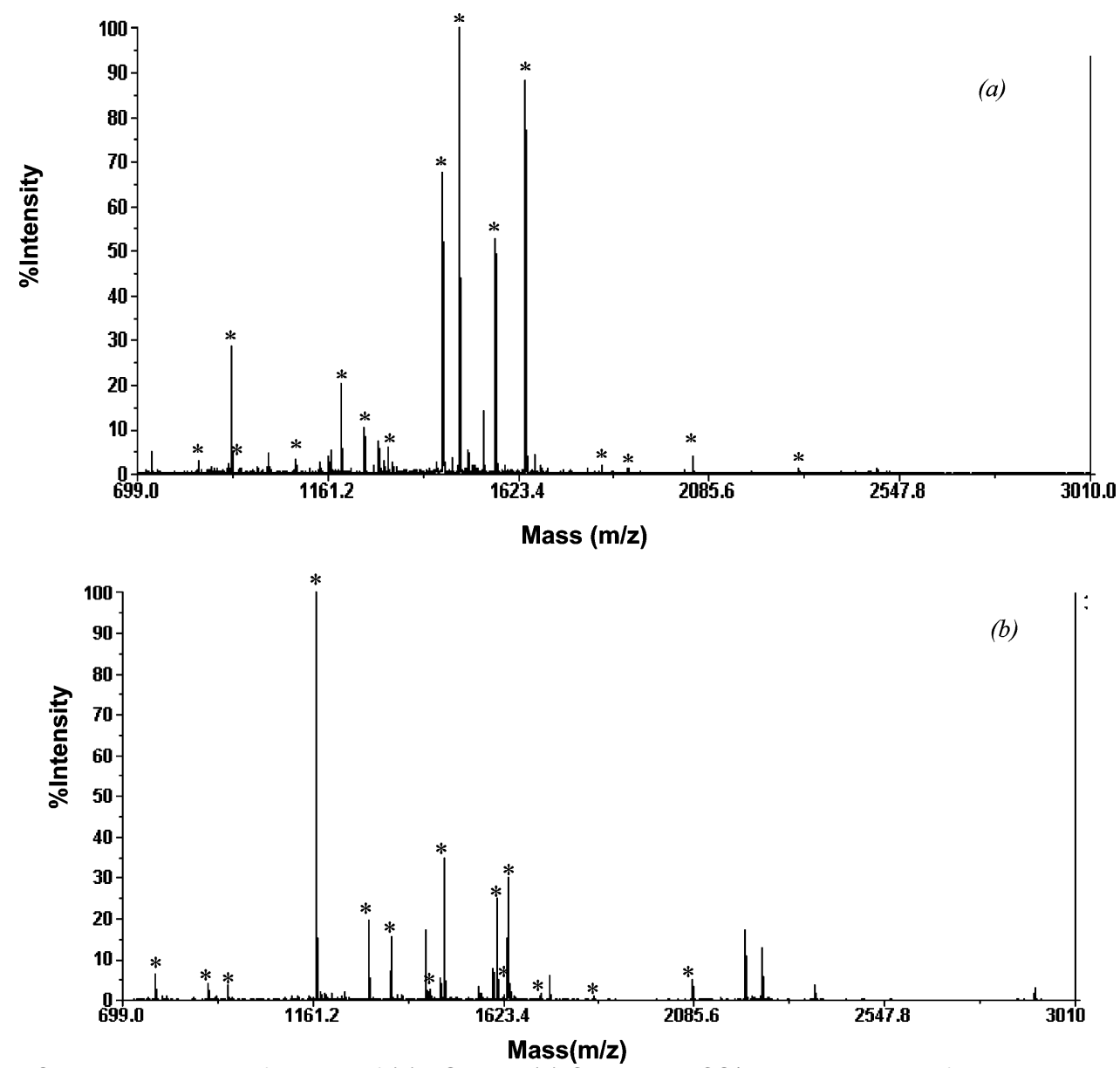

Figure 3. MALDI-TOF mass spectrum of digests of (a) BSA and (b) Cyt- $c$ using CS/HA multilayer-modified enzymatic reactor. Proteins are $0.20 \mu \mathrm{g} / \mu \mathrm{L}$ in $10 \mathrm{mmol} / \mathrm{L} \mathrm{NH}_{4} \mathrm{HCO}_{3}$ buffer solutions $(\mathrm{pH} 8.13$ ). Digestion time is $<5 \mathrm{~s}$ with a flow rate of $4.0 \mu \mathrm{L} / \mathrm{min}$. Eluent/matrix ratio is $1: 1$. 
Table 1. Summary of MALDI-TOF MS Results Obtained from Digests by Trypsin-Immobilized on-Chip Microreactorsa as Compared with in-Solution Digestion

protein

total no. fragments
amino acid sequence coverage, $\%^{b}$
protein score
digestion time
peptides matched

total no. fragments

protein score

peptides matched
BSA

microreactor
71
$38-41$
$187-215$
$<5 \mathrm{~s}$
29

Cyt-c

in solution
71
29
102
$6 \mathrm{~h}$
20

in solution

22

90

126

$6 \mathrm{~h}$

Identified Fragments with Microreactors accession no. ${ }^{c}$

\begin{tabular}{|c|c|}
\hline P02769 & P00004 \\
\hline $\begin{array}{l}\text { 25-34 DTHKSEIAHR } \\
\text { 35-44 FKDLGEEHFK } \\
\text { 66-75 LVNELTEFAK } \\
\text { 89-105 SLHTLFGDELCKVASLR } \\
\text { 139-151 LKPDPNTLDEFK } \\
\text { 157-167 FWGKYLYEIAR } \\
\text { 161-168 YLYEIARR } \\
\text { 168-183 RHPYFYAPELLYYANK } \\
\text { 205-211 IETMREK } \\
\text { 221-228 LRCASIQK } \\
\text { 223-232 CASIQKFGER } \\
\text { 242-248 LSQKFPK } \\
\text { 249-256 AEFVEVTK } \\
\text { 249-263 AEFVEVTKLVTDLTK } \\
\text { 257-263 LVTDLTK } \\
\text { 341-359 NYQEAKDAFLGSFLYEYSR } \\
\text { 347-359 DAFLGSFLYEYSR } \\
\text { 361-371 HPEYAVSVLLR } \\
\text { 361-374 HPEYAVSVLLRLAK } \\
\text { 402-412 HLVDEPQNLIK } \\
\text { 421-433 LGEYGFQNALIVR } \\
\text { 437-451 KVPQVSTPTLVEVSR } \\
\text { 438-451 VPQVSTPTLVEVSR } \\
\text { 508-523 RPCFSALTPDETYVPK } \\
\text { 529-544 LFTFHADICTLPDTEK } \\
\text { 548-557 KQTALVELLK } \\
\text { 549-561 QTALVELLKHKPK } \\
\text { 562-568 ATEEQLK } \\
\text { 588-597 EACFAVEGPK }\end{array}$ & $\begin{array}{l}\text { 8-13 KIFAQK } \\
\text { 9-22 IFVQKCAQCHTVEK } \\
\text { 26-38 HKTGPNLHGLFGRK } \\
\text { 28-38 TGPNLHGLFGR } \\
\text { 28-39 TGPNLHGLFGRK } \\
\text { 39-53 KTGQAPGFTYTDANK } \\
\text { 40-53 TGQAPGFTYTDANK } \\
\text { 40-55 TGQAPGFTYTDANKNK } \\
\text { 56-72 GITWKEETLMEYLENPK } \\
\text { 61-72 EETLMEYLENPK } \\
\text { 61-73 EETLMEYLENPKK } \\
\text { 73-79 KYIPGTK } \\
\text { 80-86 MIFAGIKK } \\
\text { 80-87 MIFAGIKK } \\
\text { 89-99 TEREDLIAYLK } \\
\text { 92-99 EDLIAYLKLK } \\
\text { 92-100 EDLIAYLKLKK }\end{array}$ \\
\hline
\end{tabular}

${ }^{a}$ Six spots replicates were taken in the experiments. ${ }^{b}$ The difference in amino acids identified and sequence coverage from chip-to-chip $(n=$ 6) ${ }^{c}$ P00004 and P02769 mean cytochrome $c$ and serum albumin precursor, respectively.

$1.6 \mathrm{mM} / \mathrm{s}$, respectively (inset line in Figure 2). The value of $V_{\max }$ per unit of trypsin was $\sim 600 \mathrm{mM} / \mathrm{min} \mu \mathrm{g}$, thousands of times faster than that in solution $(0.2 \mathrm{mM} / \mathrm{min} \mu \mathrm{g})$. The significantly increased velocity in such a microreactor might be attributed to the good biocompatible microchannel surface that could provide not only a large surface area for enzyme immobilization but also a friendly interface for preserving the bioactivity of enzymes and reducing the autoproteolysis, which could be verified in the following sensitive proteolysis.

On-Chip Protein Digestion With High Catalytic Reaction. The main application of the multilayer-modified microchip reactor is residue-specific proteolysis to generate digested fragments for protein identification. The procedure includes the digestion of proteins in a trypsin-embedding microchip, determination of the resulting fragments using MALDI-TOF MS, and identification by

(31) Sauerbrey, G. Z. Phys. 1959, 155, 206.

(32) Collings, A. F.; Caruso, F. Rep. Prog. Phys. 1997, 60, 1397-1445.

(33) Jin, W.; Shi, X. Y.; Caruso, F. J. Am. Chem. Soc. 2001, 123, 8121-8122.

(34) Zhang, L. X.; Zhang, T. F.; Li, L. Y. Methods and Techniques in Biochemistry; High Education Press: Beijing, 1997, pp 143-152. searching an appropriate database. To illustrate the efficient performance of the as-prepared microchip reactor, two standard protein samples with multiple cleavage sites, including cytochrome $c(\mathrm{MW}=12384)$ and bovine serum albumin (MW = 66000$)$, were used as model substrates for proteolysis. At a flow rate of $4.0 \mu \mathrm{L} /$ $\min , 200 \mu \mathrm{g} / \mathrm{mL}$, BSA and Cyt-c were pumped through the modified microfluidic channel, which afforded a very short residence time of less than $5 \mathrm{~s}$. The effluents from the microreactor were collected and analyzed by MALDI-TOF MS. Figure 3 displays the peptide mass fingerprinting (PMF) spectra of tryptic digests. As can be seen, the samples were identified with high signal-to-noise ratios as well as high sequence coverage. Detailed identification information is listed in Table 1. It is worth noting that a total of 29 tryptic peptides from BSA and 17 peptides from Cyt- $c$ were assigned and correspond to the amino acid sequence coverage of BSA and Cyt-c as high as 41 and $85 \%$, respectively. The identification results from the intact proteins could be comparable to those by in-solution digestion that requires a reaction time of several hours and those from other microreactors in the literature..$^{8-12}$ 

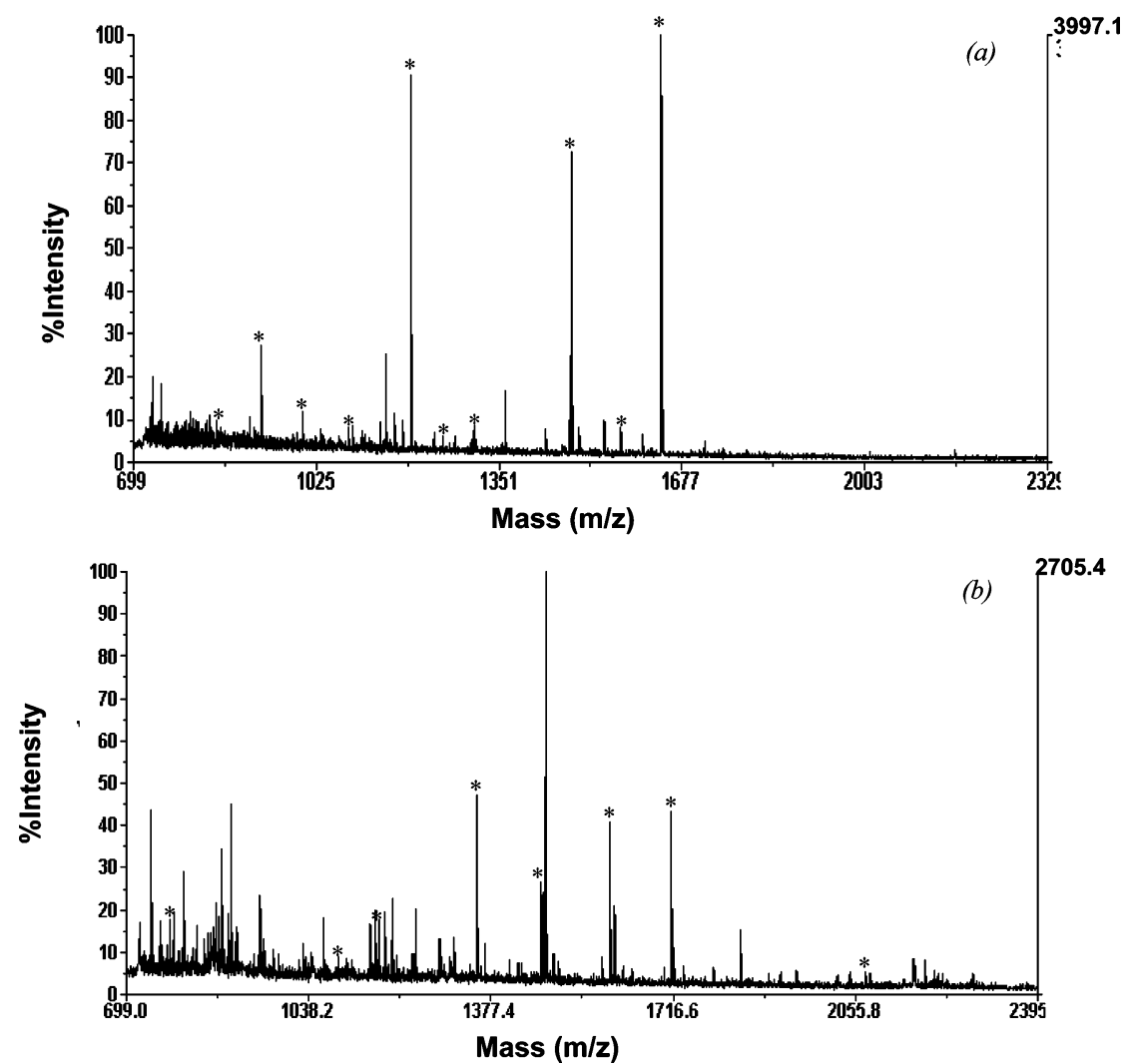

Figure 4. MALDI-TOF mass spectrum of digests of low-level protein samples (a) $5 \mathrm{ng} / \mu \mathrm{L} B S A$ and (b) $2 \mathrm{ng} / \mu \mathrm{L}$ Cyt- $c$ using the reactor. Digestion time is $<5 \mathrm{~s}$ with a flow rate of $2.0 \mu \mathrm{L} / \mathrm{min}$. Eluent/matrix ratio is $1: 1$.

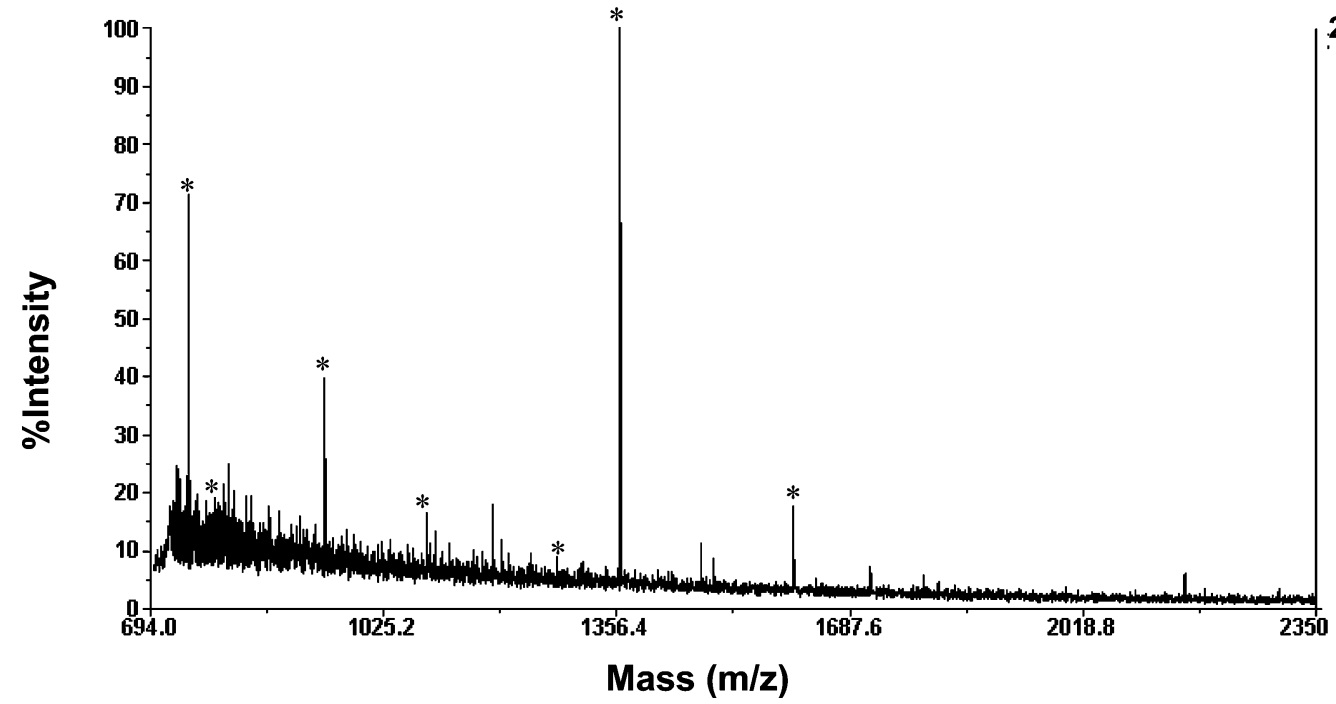

2074.3

Figure 5. MALDI-TOF mass spectrum of digests of $0.5 \mathrm{ng} / \mu \mathrm{L}$ myoglobin using the reactor. Proteins are in $2 \mathrm{mmol}^{2} \mathrm{~L} \mathrm{NH} \mathrm{NCO}_{3}$ buffer solutions. Digestion time is $<5 \mathrm{~s}$ with a flow rate of $2.0 \mu \mathrm{L} / \mathrm{min}$. Eluent/matrix ratio is $1: 1$.

As mentioned above, it is the high bioactivity of trypsin preserved in the chitosan/HA-assembled membranes that was responsible for the fast catalysis, high sequence coverage, and protein scores. The increased proteolysis velocity is mainly due to the high amounts of trypsin immobilized in the very narrow space of a microchannel (about $60 \mathrm{~nL}$ ) with a high ratio of surface area to volume. Thereby, protein substrates have more opportunities to interact with the active sites of immobilized trypsin, as compared with the soluble system. ${ }^{8}, 35$

Protein Digestion at Low Concentration. The use of immobilized enzymes in microchannels has frequently been considered as a means of increasing the enzyme concentration relative to the protein samples while minimizing enzyme autolysis, which is very useful for the high-efficiency digestion of proteins at low concentrations. By far, many approaches have been put forward, such as protein sequence tag (PST) technology, ${ }^{36}$ microcolumn capture, ${ }^{37}$ sample preconcentration, ${ }^{3}$ etc. Although these methods are available, there is still a demand for new

(35) Sakai-kato, K.; Kato, M.; Toyo’Ka, T. Anal. Chem. 2002, 74, 2943-2949.

(36) Prinz, T.; Muller, J.; Kuhn, K.; Schafer, J.; Thompson, A.; Schwarz, J.; Hamon, C. J. Proteome Res. 2004, 3, 1073-1081.

(37) Doucette, A.; Craft, D.; Li, L. Anal. Chem. 2000, 72, 3355-3362. 


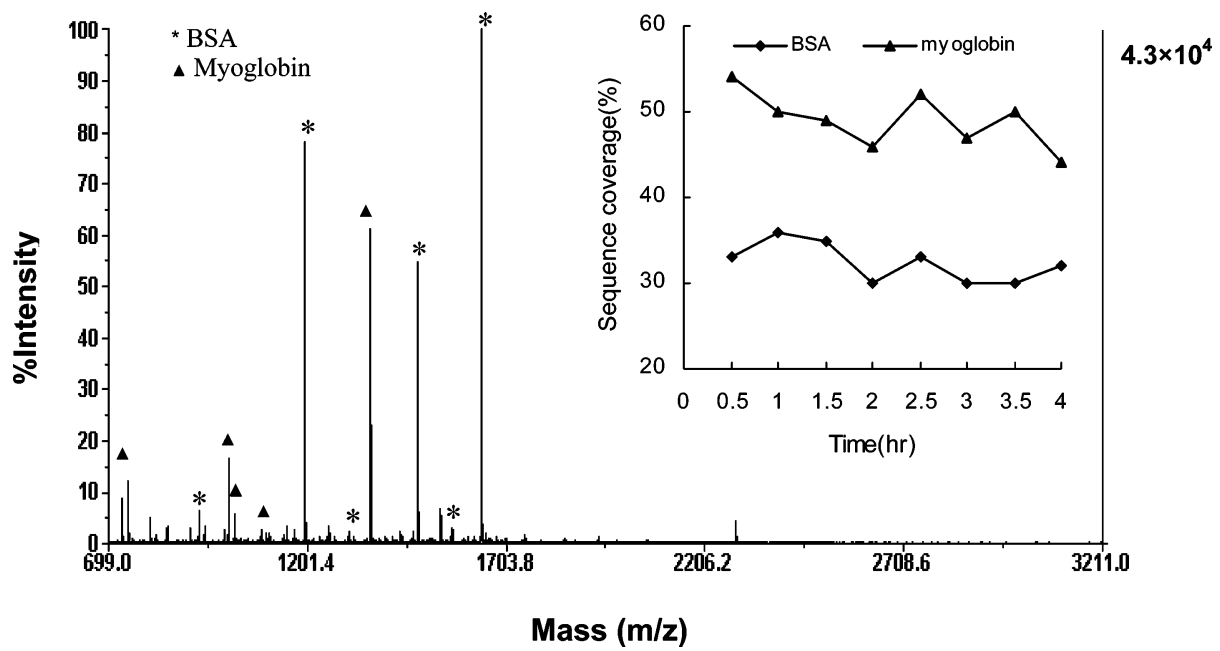

Figure 6. MALDI-TOF mass spectrum of digests of protein mixture $(100 \mathrm{ng} / \mu \mathrm{L} B S A+20 \mathrm{ng} / \mu \mathrm{L}$ myoglobin) using the CS/HA multilayermodified microchip reactor. The experimental conditions are the same as Figure 5.

sample-handling techniques. Herein, we used the chitosan/ HA-modified chip for entrapping trypsin to degrade trace amounts of proteins, and then the tryptic fragments could be identified by MALDI-TOF MS. The mass spectra of digests of $5 \mathrm{ng} / \mu \mathrm{L}$ BSA and $2 \mathrm{ng} / \mu \mathrm{L}$ Cyt- $c$ are shown in Figure $4 \mathrm{a}$ and b, resulting in 19 and 9 peptides, corresponding to 24 and $70 \%$ of the amino acid sequence of BSA and Cyt-c, respectively. The PMF spectra of digests have relatively high signal/noise ratios.

Another example of trace amount digestion is illustrated in Figure 5, where the resulting spectrum of $0.5 \mathrm{ng} / \mu \mathrm{L}(30 \mathrm{nM})$ myoglobin is shown. Myoglobin is a good model protein, because it is slightly hydrophobic and relatively difficult to digest with trypsin, in comparison with cytochrome $c$. The amino acid sequences of $28-40 \%$ with protein scores of $77-173$ were measured. No influencing enzyme autodigestion signals in the spectra. The autolysis of the immobilized trypsin, less severe in the microchip than that in solution, could be another contributor to the proteolysis acceleration. A total of $15 \mathrm{fmol}(0.25 \mathrm{ng})$ of proteins was analyzed with a reaction time $<5 \mathrm{~s}$. The sample size was 1 or 2 orders of magnitude lower than that of the conventional digestion.

Stability of the Microchip Reactor for Digestion of Proteins. The operational stability of the chip is crucial for its promising application in high-throughput bioanalysis. The mixture of $1.5 \mathrm{pmol} / \mu \mathrm{L}$ BSA and $1.2 \mathrm{pmol} / \mu \mathrm{L}$ myoglobin was digested to test the operational stability of the trypsin-immobilized reactor. The microchip was used at $37^{\circ} \mathrm{C}$ for $4 \mathrm{~h}$ in succession, and the tryptic products were analyzed with MALDI-TOF MS every 30 min. The results showed that during the experiment, the protein mixtures were successfully identified with satisfying sequence coverages of $\sim 28-36 \%$ for BSA and $\sim 44-54 \%$ for myoglobin (see Figure 6). The protein scores of $\sim 431$ to 451 for BSA and $\sim 153$ to 170 for myoglobin could be obtained, indicating that the stability and operational bioactivity of trypsin encapsulated were capable of being preserved without obvious loss. The stability of trypsin was enhanced by the prevention of autolysis in the benign environment of multilayer matrixes. Sometimes, microreactors used as rapid trypsin digestion on microchips or in capillaries have limitations. For example, the more complicated samples extracted from cells or tissues cannot be identified simultaneously. Separa- tion by means of electrophoresis, LC, or 2D-gel is a necessary procedure. Nevertheless, the microchips combined with pretreatment procedures could be favorable to long-term and highthroughput protein analysis.

\section{CONCLUSION}

A pair of biomacromolecules, positively charged chitosan and negatively charged hyaluronic acid was successfully assembled onto the surface of a PET microfluidic chip using layer-by-layer deposition for the formation of a microstructured and biocompatible scaffold to immobilize trypsin. An effective multilayerassembled microchip reactor has been developed for the rapid digestion of proteins. The unique feature of this approach is the very short digestion time, $<5 \mathrm{~s}$, and small volume of protein samples; furthermore, the preliminary results achieved with the microchip reactor are comparable to those by conventional methods. As an application, we are planning to integrate the microchip reactor with the separation procedures and MS to analyze the sequences of protein samples extracted from liver cells. Furthermore, the layer-by-layer modification technique could be used quite broadly. Functional biomolecules such as proteins, DNA, antibodies, and even cells could be encapsulated in various multilayer-assembled membranes for applications to biosensing and immunoassay.

\section{ACKNOWLEDGMENT}

This work was supported by NNSF of China (Nos. 20299030, 20575013, 30270386), 973 project 2001CB510202 and 2004CB520804, Shanghai Sci\&Tech Develop Program 03DZ14024 and 05QMH1402, and EPFL via an academic visitor fellowship to B.H.L. The authors thank Valerie Devaud for her technical help.

\section{SUPPORTING INFORMATION AVAILABLE}

Additional information as noted in text. This material is available free of charge via the Internet at $\mathrm{http} / / /$ pubs.acs.org.

Received for review August 15, 2005. Accepted November 24, 2005.

AC051463W 